\title{
Sex differences in the inflammatory response of primary astrocytes to lipopolysaccharide
}

\author{
María Santos-Galindo, Estefanía Acaz-Fonseca, María J Bellini and Luis M Garcia-Segura*
}

\begin{abstract}
Background: Numerous neurological and psychiatric disorders show sex differences in incidence, age of onset, symptomatology or outcome. Astrocytes, one of the glial cell types of the brain, show sex differences in number, differentiation and function. Since astrocytes are involved in the response of neural tissue to injury and inflammation, these cells may participate in the generation of sex differences in the response of the brain to pathological insults. To explore this hypothesis, we have examined whether male and female astrocytes show a different response to an inflammatory challenge and whether perinatal testosterone influences this response.
\end{abstract}

Methods: Cortical astrocyte cultures were prepared from postnatal day 1 (one day after birth) male or female CD1 mice pups. In addition, cortical astrocyte cultures were also prepared from female pups that were injected at birth with $100 \mu \mathrm{g}$ of testosterone propionate or vehicle. Cultures were treated for 5 hours with medium containing lipopolysaccharide (LPS) or with control medium. The mRNA levels of IL6, interferon-inducible protein 10 (IP10), TNF $\alpha$, IL $1 \beta$, Toll-like receptor 4 (TLR4), steroidogenic acute regulatory protein and translocator protein were assessed by quantitative real-time polymerase chain reaction. Statistical significance was assessed by unpaired t-test or by one-way analysis of variance followed by the Tukey post hoc test.

Results: The mRNA levels of IL6, TNF $\alpha$ and IL $1 \beta$ after LPS treatment were significantly higher in astrocytes derived from male or androgenized females compared to astrocytes derived from control or vehicle-injected females. In contrast, IP10 mRNA levels after LPS treatment were higher in astrocytes derived from control or vehicle-injected females than in those obtained from males or androgenized females. The different response of male and female astrocytes to LPS was due neither to differences in the basal expression of the inflammatory molecules nor to differences in the expression of the LPS receptor TLR4. In contrast, the different inflammatory response was associated with increased mRNA levels of translocator protein, a key steroidogenic regulator, in female astrocytes that were treated with LPS.

Conclusions: Male and female cortical astrocytes respond differentially to an inflammatory challenge and this may be predetermined by perinatal testosterone exposure.

Keywords: IFN-inducible protein 10, IL1 $\beta$, IL6, steroidogenic acute regulatory protein, testosterone, Toll-like receptor 4, translocator protein $18 \mathrm{kDa}$, TNFa

\section{Background}

Astrocytes, one of the glial cell types of the central nervous system (CNS), are involved in a variety of functions under physiological conditions, including the control of brain blood flow and neuronal metabolism [1,2]. In addition, astrocytes regulate extracellular potassium levels and neuronal excitability and, by means of astrocyte-astrocyte and astrocyte-neuron communication, participate in the

\footnotetext{
* Correspondence: Imgs@cajal.csic.es

Instituto Cajal, CSIC, Avenida Doctor Arce 37, E-28002 Madrid, Spain
}

regulation of synaptic transmission, synaptic plasticity and information processing in the CNS [3,4]. Astrocytes also play an important role under pathological conditions. Together with microglia, these cells participate in the local inflammatory response of the CNS, releasing a variety of inflammatory mediators, including cytokines, such as IL6, TNF $\alpha$ and IL1 $\beta$, and chemokines, such as IFN-inducible protein 10 (IP10) [5-7]. Astrocytes also express Toll-like receptor 4 (TLR4), which mediates the inflammatory actions of lipopolysaccharide (LPS) in these cells [8-12].

\section{(Ciomed Central}


Sex differences in the number, differentiation and function of astrocytes [13-24] are associated in several CNS regions with sex differences in the structure and function of neuronal circuits $[17,25,26]$ and are thought to participate in the generation of sex differences in neuroendocrine regulation, behavior and cognition. In addition, sex differences in astrocytes are relevant under pathological conditions. Numerous neurological and psychiatric disorders, including Parkinson's disease, Alzheimer's disease, Huntington's disease, multiple sclerosis, traumatic brain injury, stroke, autism, schizophrenia, depression, anxiety disorders, eating disorders and peripheral neuropathy, show sex differences in incidence, age of onset, symptomatology and outcome [27-31]. It is plausible that sex differences in astrocytes might be involved in the generation of sex differences in the manifestation of brain pathological alterations. In this regard, previous studies have shown that cortical astrocytes from male mice are less resistant than those from female mice to oxygenglucose deprivation [32]. This sex difference may be due to different activity of the enzyme aromatase, which converts testosterone into estradiol; aromatase activity is higher in cortical female astrocytes than in cortical male astrocytes [32]. Since aromatase activity is neuroprotective $[33,34]$, the sexually dimorphic activity of the enzyme in astrocytes may contribute to protect not only these cells but also other CNS cell types, including neurons, from damage.

Furthermore, astrocytes express other enzymes involved in steroid synthesis and metabolism [35] and release a variety of neuroprotective steroids, such as pregnenolone, progesterone and its reduced metabolites, dihydroprogesterone and tetrahydroprogesterone [36-42], which may influence the outcome of neurodegenerative diseases. In addition, astrocytes express steroidogenic acute regulatory protein (StAR) and translocator protein of $18 \mathrm{kDa}$ (TSPO, previously known as peripheral benzodiazepine receptor) [43-45]. These proteins are involved in the first step of steroidogenesis: the conversion of cholesterol into pregnenolone by the enzyme P450scc. This step is highly regulated by the activity of several proteins, such StAR and TSPO, which facilitate the transport of cholesterol through the hydrophilic space located between the outer and inner mitochondrial membranes, where P450scc is located $[45,46]$.

While the responses of astrocytes to pathological conditions are well documented, the possible existence of sex differences in these responses has received less attention. Therefore, in this study, we have assessed whether cortical astrocytes derived from male and female mice have a different reaction to an inflammatory challenge induced by LPS and whether this is associated with differences in the expression of two main steroidogenic regulators: StAR and TSPO. We have assessed the expression of IL6, TNF $\alpha$, IL1 $\beta$ and IP10. These molecules were selected because their expression is altered in the CNS under different pathological conditions, including Alzheimer's disease, Parkinson's disease, multiple sclerosis and traumatic brain injury [7]. We have also explored whether the perinatal peak of androgens, which participate in the sex differentiation of the CNS in rodents [47], may influence the subsequent inflammatory response of astrocytes to LPS. Our results indicate that cortical primary astrocytes derived from male and female mice pups show different expression of inflammatory markers in response to LPS. This difference is associated with increased expression of TSPO in female astrocytes exposed to LPS. In addition, our findings suggest that perinatal testosterone might be involved in the sexually dimorphic inflammatory response of astrocytes.

\section{Results}

\section{Astrocytes from males and females expressed different mRNA levels of IL6, IP10, TNF $\alpha$ and IL1 $\beta$ after LPS exposure}

The mRNA levels of IL6, IP10, TNF $\alpha$ and IL1 $\beta$ were first assessed in astrocytes from cultures not treated with LPS. The results indicate that, under basal conditions, cultures obtained from postnatal day 1 (PND1) male and female pups expressed similar mRNA levels of these cytokines (Figure 1).

LPS treatment increased the mRNA levels of IL6, IP10, TNF $\alpha$ and IL1 $\beta$ in the cultures from both male and female mice. However, the increase in mRNA levels of IL6, TNF $\alpha$ and IL1 $\beta$ was significantly higher in the cultures obtained from male pups. In contrast, the increase in IP10 mRNA levels was higher in the cultures obtained from females (Figure 2).

\section{Astrocytes from control and androgenized females expressed different mRNA levels of IL6, IP10, TNF $\alpha$ and IL1 $\beta$ after LPS exposure}

To explore the basis of the sex differences detected in the previous experiment, we obtained astrocyte cultures from females treated 24 hours earlier, on PND0, with testosterone propionate and from control females injected on PND0 with vehicle. No significant differences in the levels of IL6, IP10, TNF $\alpha$ and IL1 $\beta$ were detected under basal conditions (Figure 3).

LPS treatment increased the mRNA levels of IL6, IP10, TNF $\alpha$ and IL1 $\beta$ in all cultures. However, the increase in mRNA levels of IL6, TNF $\alpha$ and IL1 $\beta$ was higher in the cultures obtained from androgenized females, whereas the increase in IP10 mRNA levels was higher in the cultures obtained from control females (Figure 4). 

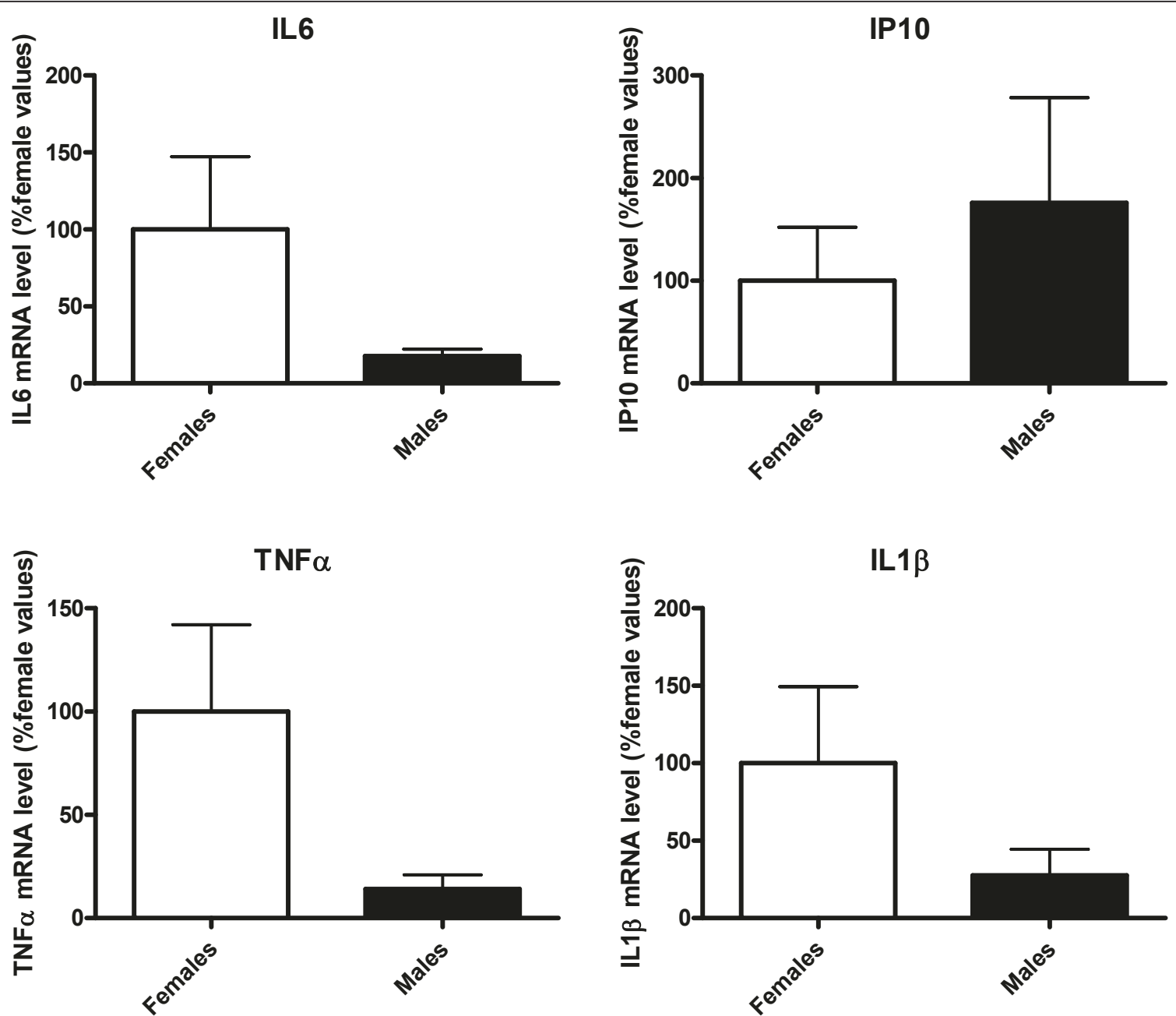

Figure 1 Male and female astrocytes express similar mRNA levels of interleukin 6 , IFN-inducible protein 10 , TNF $\alpha$ and interleukin $1 \beta$ mRNA levels of interleukin 6 (IL6), IFN-inducible protein 10 (IP10), TNF $\alpha$ and interleukin $1 \beta$ (IL1 $\beta$ ) in cortical astrocyte cultures from male and female mouse pups under basal conditions are shown. Data are means \pm standard errors of the mean (SEM) and are expressed as percentages of female values. No statistically significant differences were detected.

Astrocytes from males and females expressed similar mRNA levels of TLR4 under basal conditions and after LPS exposure

To determine whether the sexually dimorphic response to LPS was due to different expression levels of the LPS receptor TLR4 in male and female astrocytes, we measured the mRNA levels of TLR4 in control and LPStreated astrocyte cultures. No significant differences were detected in the basal mRNA levels of TLR4 between the cultures derived from male and female pups. In addition, TLR4 mRNA levels were not significantly affected by treatment with LPS (Figure 5).

Astrocytes from males and females showed different regulation of TSPO mRNA levels after LPS exposure

To determine whether the sex differences observed in the response of IL6, IP10, TNF $\alpha$ and IL1 $\beta$ mRNA levels to
LPS were associated with sex differences in the expression of steroidogenic proteins, we assessed the mRNA levels of two proteins involved in cholesterol transport to the mitochondria: TSPO and StAR. No significant differences were detected in the mRNA levels of TSPO and StAR between cultures from males and females under basal conditions. However, LPS increased the mRNA levels of TSPO in the cultures from females, but not in the cultures from males. LPS did not affect StAR mRNA levels (Figure 6).

\section{Discussion}

In this study, we have assessed the expression of IL6, IP10, TNF $\alpha$ and IL1 $\beta$ by cultured astrocytes derived from the cerebral cortices of neonatal male and female mice. The mRNA levels of these inflammatory markers increased in both male and female astrocytes after incubation with 


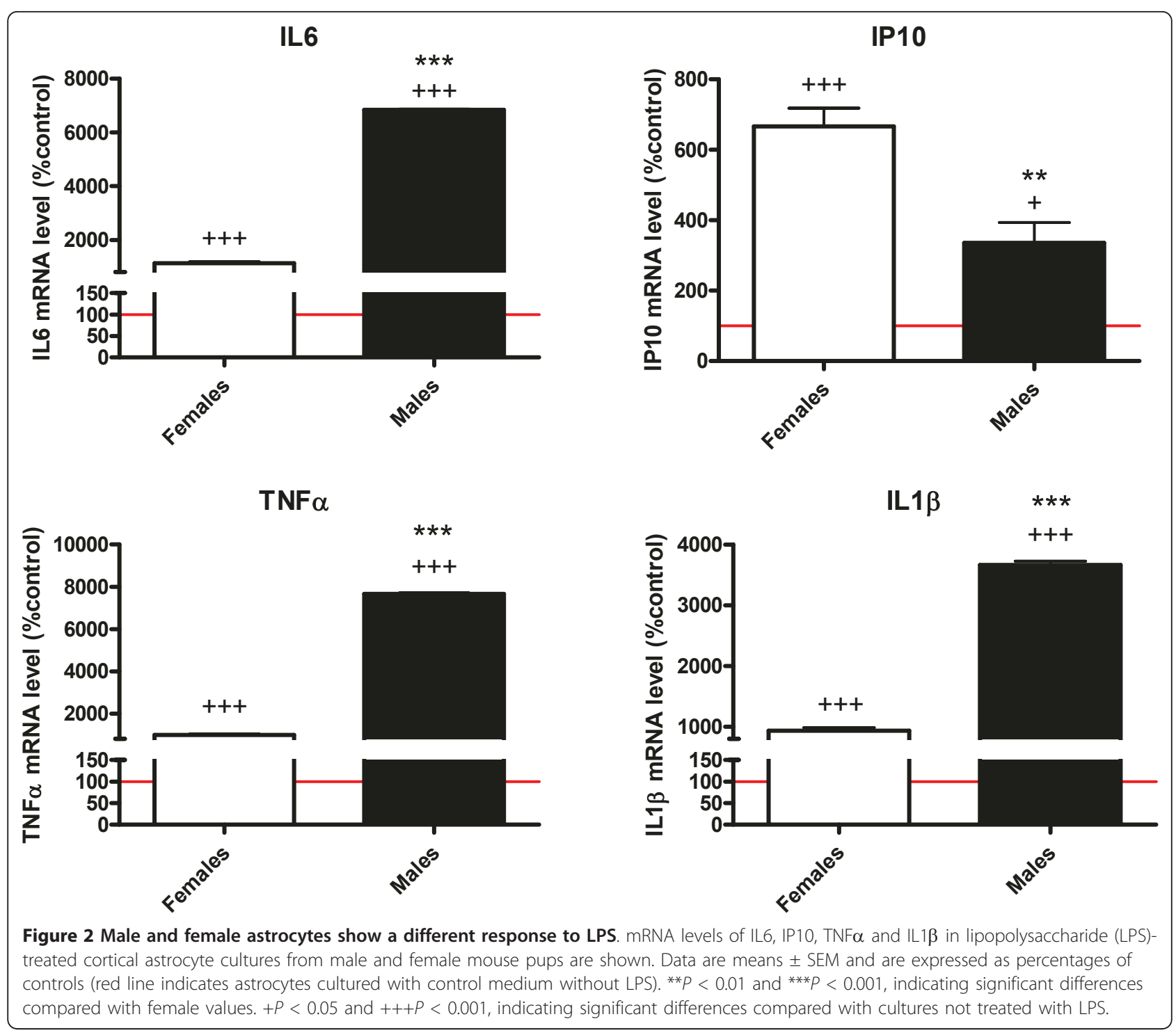

LPS. These findings are in agreement with previous studies showing that LPS induces an inflammatory response in cultured astrocytes $[5,12,48]$. However, our present results indicate that male and female astrocytes differ in the characteristics of their inflammatory response. In response to LPS, male astrocytes showed enhanced expression of IL6, TNF $\alpha$ and IL1 $\beta$, while female astrocytes showed enhanced expression of IP10. In contrast, under basal unstimulated conditions, astrocytes from males and females showed similar mRNA levels of IL6, IP10, TNF $\alpha$ and IL1 $\beta$. This suggests that it is the response of astrocytes to LPS that is sexually dimorphic, not the mechanisms that regulate the basal expression of IL6, TNF $\alpha$, IL1 $\beta$ and IP10.

The inflammatory response to LPS is mediated by TLR4, a member of the IL1 receptor/TLR superfamily that is expressed by astrocytes [8-12]. Our findings indicate that TLR4 mRNA levels are not significantly different between male and female astrocytes both under resting conditions and after LPS treatment, suggesting that the sex difference in the inflammatory response of astrocytes is not mediated by different expression of LPS receptors. However, we cannot exclude differences in TLR4 signaling between male and female astrocytes as a mediating factor\}.

Sex differences in the manifestation of several neurodegenerative diseases are associated with differences in local steroid levels in the CNS $[49,50]$. Astrocytes express proteins such as TSPO that are involved in the transport of cholesterol from the outer to the inner mitochondrial membrane, where P450scc, the first enzyme of the steroidogenic pathway, is located [35,51]. Therefore, astrocytes can convert cholesterol in pregnenolone by the enzyme P450scc. In addition, rodent astrocytes express all the 


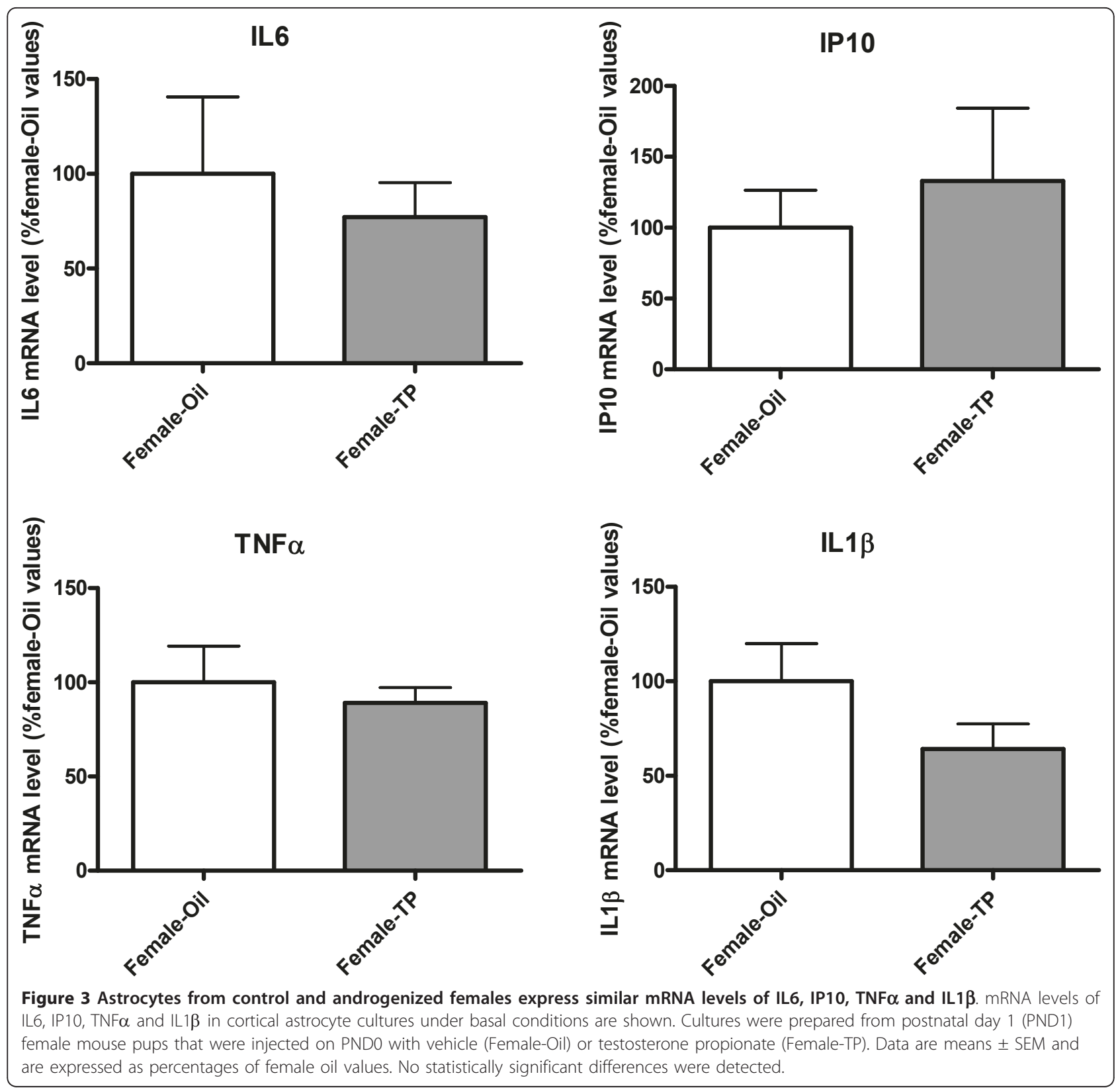

steroidogenic enzymes necessary to metabolize pregnenolone in other steroids, such as progesterone and estradiol [35]. Since some of the steroids derived from pregnenolone have anti-inflammatory properties and reduce astrogliosis [52-55], and since TSPO expression is increased after different forms of neural injury [56-58], we examined whether LPS could induce changes in TSPO expression in astrocytes. Previous studies have shown that TSPO is involved in the control of reactive gliosis $[59,60]$ and regulates several mitochondrial functions, including the control of apoptosis [61,62], which may also affect the inflammatory response. Our findings indicate that LPS increases the levels of TSPO in cultured astrocytes derived from female mice, but not in astrocyte cultures derived from male mice. However, the mRNA levels of TSPO were not different between female astrocytes stimulated with LPS and male astrocytes under basal and LPS-stimulated conditions. Therefore, it is unclear whether the different responses of TSPO to LPS between male and female astrocytes are sufficient to explain the sexually dimorphic inflammatory responses of these cells.

We also analyzed the effect of LPS on the expression of StAR, another molecule involved in the transport of cholesterol to the mitochondria $[44,45]$. In the brain in vivo, StAR is expressed in specific populations of 


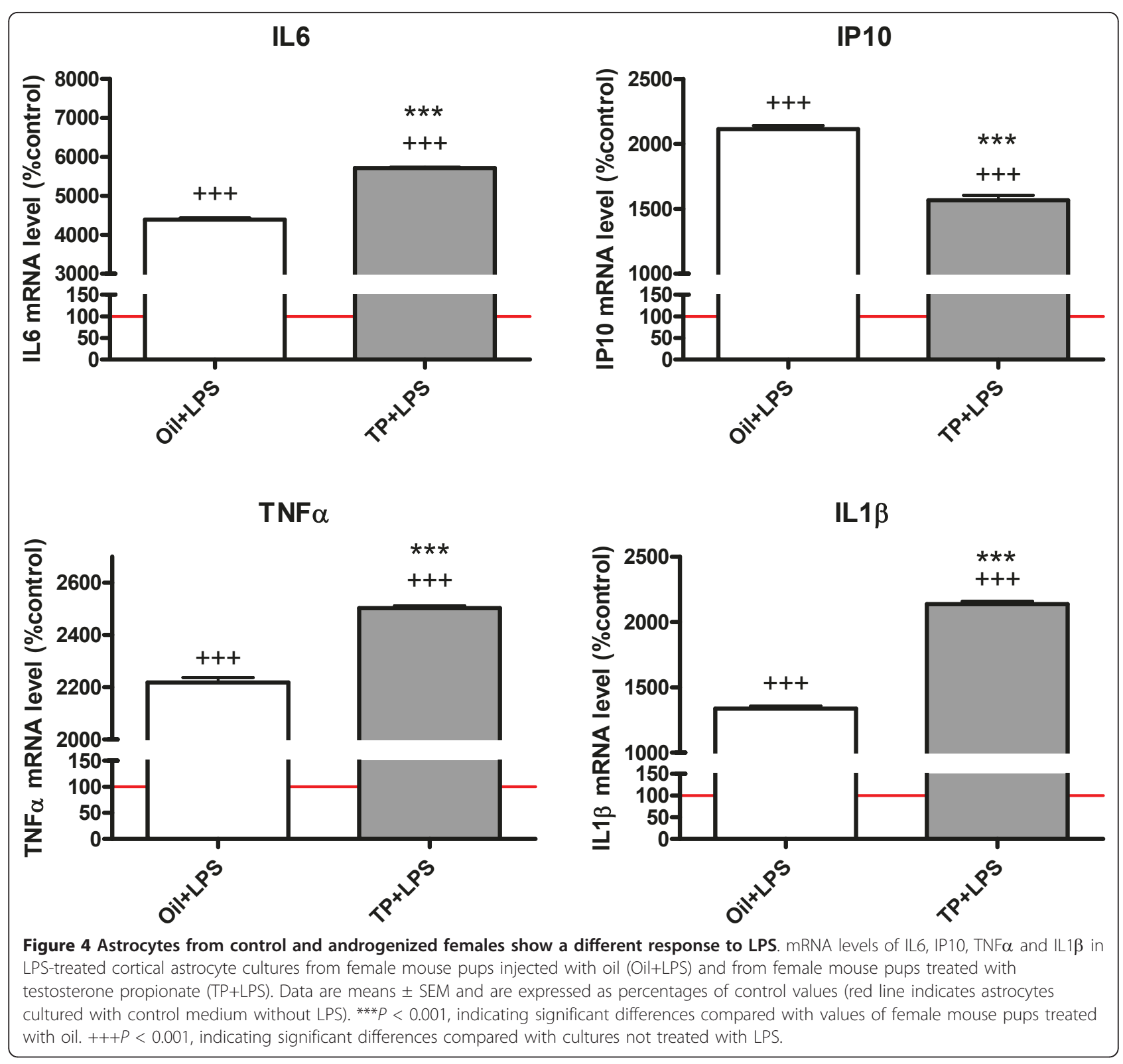

astrocytes and neurons, although most cells expressing the protein are neurons $[45,63]$. As for TSPO, previous studies have shown that StAR expression is increased in the CNS after injury [63,64]. However, in contrast to TSPO, LPS did not induce a change in the expression of StAR mRNA in astrocytes. In addition, we did not detect a difference in StAR expression between male and female astrocytes. However, we cannot exclude the possibility of differences in StAR activity, which is regulated by posttranslational modifications of the protein [45].

Sex differences in astrocytes can result from direct sex chromosome differences in these cells and/or from different exposure to sex steroids during development [65].
Previous in vivo studies have shown that perinatal actions of androgens are involved in the generation of sex differences in the expression of glial fibrillary acidic protein and in the differentiation and number of astrocytes in different brain regions $[13,20,23,66]$. Our findings indicate that astrocyte cultures derived from female pups that were androgenized on PD0 show a response to LPS similar to that of astrocyte cultures derived from male pups. Thus, LPS induced an increase in the mRNA levels of IL6, TNF $\alpha$ and IL1 $\beta$ in the cultures obtained from males and androgenized females compared to control females. In contrast, LPS induced an increase in IP10 mRNA levels in the cultures obtained from control females compared to the cultures obtained from males 


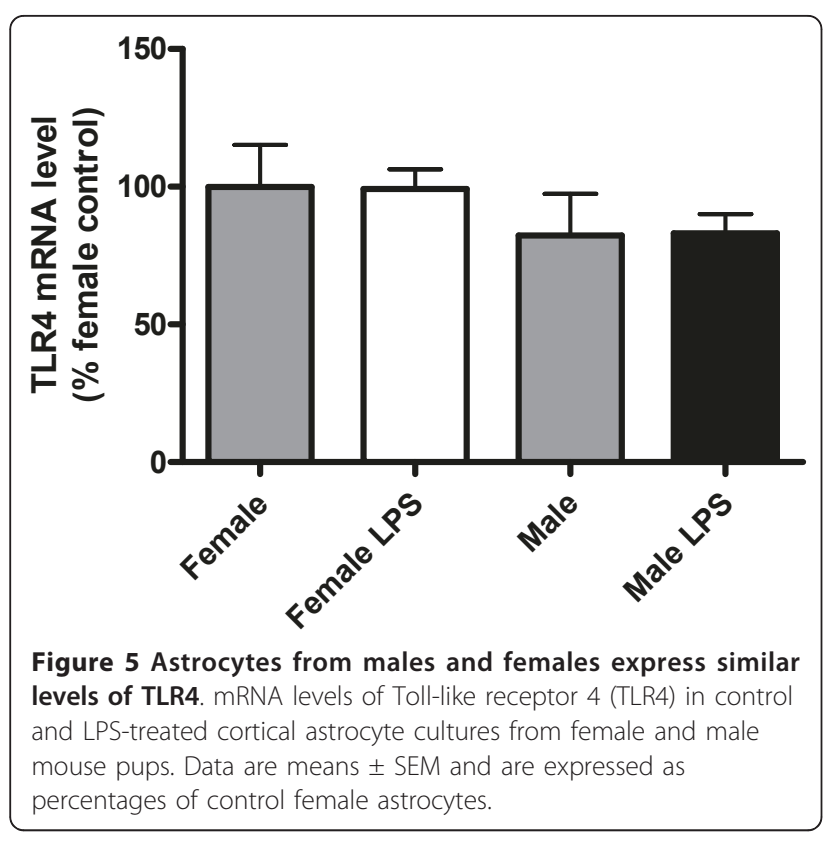

and androgenized females. Therefore, it seems that the action of testosterone on astrocytes on PD0 is able to produce modifications in these cells that are maintained even after their extraction from the brain and their regrowth in vitro.

Our findings showing sex differences in the inflammatory response of astrocytes are consistent with previous observations indicating that female astrocytes are more resistant than male astrocytes to oxygen-glucose deprivation and oxidant-induced cell death [32,67]. If translatable to in vivo conditions, the different in vitro inflammatory responses of male and female astrocytes detected in this study could contribute to sex differences in the manifestation of neurodegenerative diseases. For instance, different expression of IP10 between male and female astrocytes in vivo could result, in sex differences in the recruitment of $\mathrm{T}$ lymphocytes, natural killer cells and monocytes into the CNS $[68,69]$. Sex differences in the expression of IL1 $\beta$ by astrocytes in vivo could result in sex differences in neuronal injury [70] and in the remyelination of multiple sclerosis lesions [71]. Enhanced IL6 production by male astrocytes could result in sex differences in the outcome of acute and chronic pathological conditions, since astrocyte-driven production of IL6 in vivo increases chronic inflammatory damage [72] but protects the CNS against acute focal injury [73-75]. Finally, different production of TNF $\alpha$ by male and female astrocytes could result in sex differences in microglial reactivity [76], dysfunction of the blood-brain barrier [77] and the survival of oligodendrocyte precursors [78,79]. Therefore, further studies should explore the functional consequences of the different inflammatory responses of male and female astrocytes and whether this sexually dimorphic response affects astrocytes' survival, activation, proliferation and ability to protect neurons and oligodendrocytes under pathological conditions.

\section{Conclusions}

In summary, our findings indicate that primary cortical astrocytes in mice respond differently to an inflammatory challenge, depending on whether they are obtained from males or females. In addition, primary astrocytes derived from perinatally androgenized females respond to inflammatory challenges in the same way that primary astrocytes derived from males do, suggesting that perinatal testosterone programs astrocytes for a different

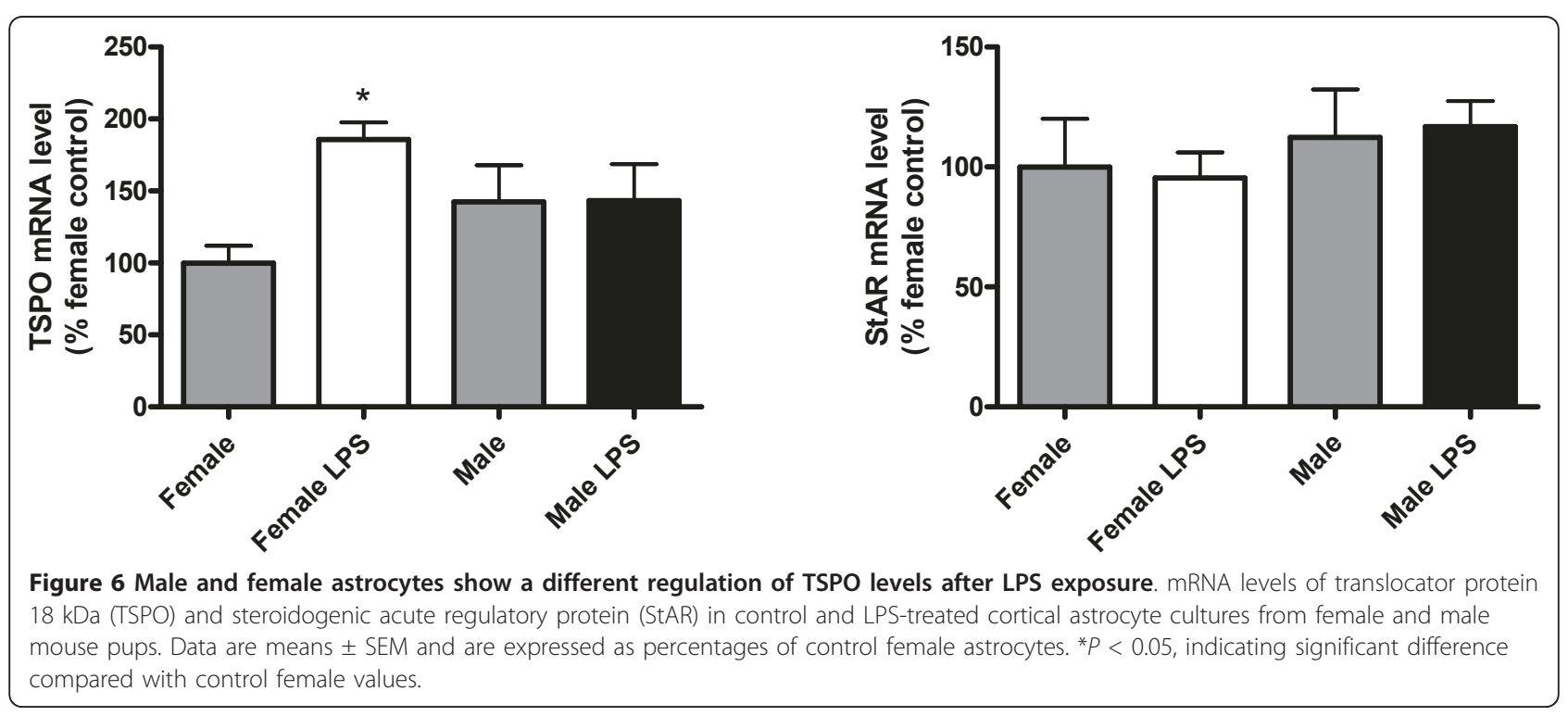


response to pathological conditions. These sex differences with regard to astrocytes may be relevant to the generation of sex differences in brain pathology.

\section{Methods}

\section{Animals and in vivo treatments}

CD1 mice dams from the Instituto Cajal animal colony were kept on a 12-hour light-dark schedule and received food and water ad libitum until birth. Male and female pups were distinguished by a larger genital papilla and longer anogenital distance in male pups than in female pups. Experimental procedures were approved by our Institutional Animal Use and Care Committee (Spanish National Research Council Animal Experimentation Committee). Special care was taken to minimize suffering and to reduce the number of animals used to the minimum required for statistical accuracy.

In a first set of experiments, PND1 male and female pups were used to obtain cortical astrocyte cultures. In a second set of experiments, female pups were injected at birth (PND0) with $50 \mu \mathrm{L}$ of corn oil (vehicle) or $100 \mu \mathrm{g}$ of testosterone propionate (diluted $2 \mathrm{mg} / \mathrm{mL}$; Fluka Chemie, Buchs, Switzerland). Cortical astrocyte cultures were obtained from these females on PND1, 24 hours after the administration of testosterone propionate or vehicle. The subsequent processing was the same in both sets of experiments.

Cortical astrocyte primary cultures and in vitro treatments Astrocytes were cultured from PND1 male and CD1 female mice pups separately. The brain was extracted, the meninges were removed and the entire neocortex was isolated under a dissecting microscope. Next, the cortex was dissociated mechanically, washed twice in Hank's balanced salt solution (Invitrogen, Paisley, UK) and filtered through a 40- $\mu \mathrm{m}$ nylon cell strainer into phenol red-free DMEMF12 (Invitrogen, Paisley, UK) containing 10\% fetal bovine serum (FBS; Invitrogen) and penicillin-streptomycin (Invitrogen). After centrifugation at 1,000 rpm for 5 minutes, cells were resuspended and cultured in $75-\mathrm{cm}^{2}$ tissue culture flasks at $37^{\circ} \mathrm{C}$ and $5 \% \mathrm{CO}_{2}$. The medium was changed after one day in vitro and subsequently two times per week until the cells reached confluence. Next, enriched astrocyte cultures were obtained after overnight shaking at $37^{\circ} \mathrm{C}$ and $280 \mathrm{rpm}$ on a tabletop shaker (Thermo Forma, Marietta, OH, USA) to minimize oligodendrocyte and microglia contamination. Astrocytes were removed from the flasks by incubation with $0.5 \%$ trypsin (type II-S; Sigma-Aldrich, St Louis, MO, USA) and 0.04\% ethylenediaminetetraacetic acid (Sigma-Aldrich). Trypsinization was stopped with DMEM-F12 medium with FBS, the cell suspension was centrifuged and the pellet was resuspended and plated onto poly-L-lysine-coated six-well plates in serum-free medium and used within 24 hours.
One day after plating astrocytes were treated for 5 hours with medium containing LPS (500 ng/mL LPS, Escherichia coli 026:B6; Sigma-Aldrich) or with control medium without LPS. The dose of LPS was based on that used in a previous study [5].

\section{Quantitative real-time polymerase chain reaction}

After 5 hours of treatment with LPS, culture medium was removed and cells were lysed. Total RNA was extracted using the illustra RNAspin Mini RNA Isolation Kit (GE Healthcare, Buckinghamshire, UK) to assess the mRNA expression levels of IL6, IP10, TNF $\alpha$, IL1 $\beta$, TLR4, StAR and TSPO.

First-strand cDNA was prepared from $1 \mu \mathrm{g}$ of RNA using M-MLV Reverse Transcriptase (Promega, Madison, WI, USA) according to the manufacturer's protocol. After reverse transcription, the cDNA was diluted 1:4 for the unknown gene and 1:100 for the endogenous control, and $5 \mu \mathrm{L}$ of these cDNA solutions were amplified by real-time PCR in a $15 \mu \mathrm{L}$ voulme reaction using SYBR Green PCR MasterMix (Applied Biosystems, Foster City, CA, USA) or TaqMan Universal PCR MasterMix (Applied Biosystems) using the ABI Prism 7500 Sequence Detection System (Applied Biosystems) with conventional Applied Biosystems cycling parameters (40 cycles of changing temperatures, first at $95^{\circ} \mathrm{C}$ for 15 seconds and then at $60^{\circ} \mathrm{C}$ for 1 minute). The primer sequences were designed using Primer Express software (Applied Biosystems) and are shown in Table 1.

Glyceraldehyde 3-phosphate dehydrogenase (GAPDH) was selected as a control housekeeping gene. The GAPDH TaqMan probes and primers used were the Assays-on-Demand Gene Expression Products (Applied Biosystems). After amplification, a denaturing curve was performed to ensure the presence of unique amplification products.

To visualize and sequence the PCR products, each amplification product was electrophoresed on $2 \%$ (wt/ vol) ethidium bromide-stained agarose gel. Next, bands were excised and cDNA was purified using the QIAquick PCR Purification Kit (Qiagen Iberia, Madrid, Spain). Samples were sequenced (Automatic Sequencing Center, CSIC, Madrid, Spain) with the corresponding forward or reverse primer. The obtained sequence was aligned with the expected sequence of each transcript obtained from GenBank. All reactions were performed in duplicate, and the quantities of target gene expression were normalized to the corresponding GAPDH expression in test samples and plotted.

\section{Statistical analysis}

Statistical significance was assessed by performing an unpaired $t$-test for the one-to-one comparisons and one-way analysis of variance followed by the Tukey post 
Table 1 Primer sequences used for quantitative real-time polymerase chain reaction ${ }^{\mathrm{a}}$

\begin{tabular}{|c|c|c|}
\hline Gene & Forward Primer & Reverse Primer \\
\hline IL6 & 5'-GAAACCGCTATGAAGTTCCTCTCTG-3' & 5'-TGTTGGGAGTGGTATCCTCTGTGA-3 \\
\hline IP10 & 5'-CAGTGAGAATGAGGGCCATAGG-3' & 5'-CGGATTCAGACATCTCTGCTCAT-3' \\
\hline TNF $\alpha$ & $5^{\prime}$-GAAAAGCAAGCAGCCAACCA-3' & 5'- CGGATCATGCTTTCTGTGCTC -3' \\
\hline IL $1 \beta$ & 5'- CGACAAAATACCTGTGGCCT -3' & 5'- TTCTTTGGGTATTGCTTGGG -3' \\
\hline StAR & 5'-GTCCCTCCAAGACTAAACTCACTTG-3' & 5'-GGTGGTTGGCGAACTCTATCTG-3' \\
\hline TLR4 & 5'-GGCTCCTGGCTAGGACTCTGA-3' & 5'-TCTGATCCATGCATTGGTAGGT-3' \\
\hline TSPO & 5'-TGCAGAAACCCTCTTGGCATC-3' & 5'-TGAAACCTCCCAGCTCTTTCC-3' \\
\hline
\end{tabular}

IL6, interleukin 6; IP10, IFN-inducible protein 10; TNF $\alpha$, tumor necrosis factor $\alpha$; IL1 $\beta$, interleukin 1 $\beta$; StAR, steroidogenic acute regulatory protein; TLR4, Toll-like receptor 4; TSPO, translocator protein of $18 \mathrm{kDa}$.

hoc test for comparisons with more than two experimental groups. GraphPad Prism 5 software (GraphPad Software, San Diego, CA, USA) was used for the analysis. The significance level was set at $P<0.05$. Data shown in the figures are the results of three to seven independent experiments and data are presented as the mean \pm standard error of the mean.

\section{Abbreviations \\ CNS: central nervous system; DMEM: Dulbecco's modified Eagle's medium; IL: interleukin; IFN: interferon; IP10: IFN-inducible protein 10; LPS: lipopolysaccharide; PCR: polymerase chain reaction; StAR: steroidogenic acute regulatory protein; TLR4: Toll-like receptor 4; TNFa: tumor necrosis factor a; TSPO: translocator protein of $18 \mathrm{kDa}$.}

\section{Acknowledgements}

This work was supported by grant BFU2008-02950-C03-01 from the Ministerio de Ciencia e Innovación, Madrid, Spain. MSG is the recipient of a Junta de Ampliación de Estudios (JAE) predoctoral fellowship from Consejo Superior de Investigaciones Científicas (CSIC), Madrid, Spain. We thank María Mauriño for excellent technical assistance. Publication costs were supported in part by the Society for Women's Health Research.

\section{Authors' contributions}

MSG and LMGS have designed the experiments and interpreted the data and have been involved in the writing of the manuscript. MSG, EAF and MJB have acquired the data and analyzed the experiments. All the authors have revised the manuscript and given final approval of the version to be published.

\section{Competing interests}

The authors declare that they have no competing interests.

Received: 4 April 2011 Accepted: 11 July 2011 Published: 11 July 2011

\section{References}

1. Magistretti PJ: Neuron-glia metabolic coupling and plasticity. J Exp Biol 2006, 209:2304-2311.

2. Attwell D, Buchan AM, Charpak S, Lauritzen M, Macvicar BA, Newman EA: Glial and neuronal control of brain blood flow. Nature 2010, 468:232-243.

3. Gundersen V, Volterra A: Glutamate exocytosis from astrocytes controls synaptic strength. Nat Neurosci 2007, 10:331-339.

4. Araque A, Navarrete M: Glial cells in neuronal network function. Philos Trans R Soc Lond B Biol Sci 2010, 365:2375-2381.

5. Cerciat M, Unkila M, Garcia-Segura LM, Arevalo MA: Selective estrogen receptor modulators decrease the production of interleukin- 6 and interferon- $y$-inducible protein- 10 by astrocytes exposed to inflammatory challenge in vitro. Glia 2010, 58:93-102.

6. Bellini MJ, Hereñú CB, Goya RG, Garcia-Segura LM: Insulin-like growth factor-I gene delivery to astrocytes reduces their inflammatory response to lipopolysaccharide. J Neuroinflammation 2011, 8:21.
7. Dong Y, Benveniste EN: Immune function of astrocytes. Glia 2001, 36:180-190.

8. Blanco AM, Valles SL, Pascual M, Guerri C: Involvement of TLR4/type I IL-1 receptor signaling in the induction of inflammatory mediators and cell death induced by ethanol in cultured astrocytes. $J$ Immunol 2005, 175:6893-6899.

9. Krasowska-Zoladek A, Banaszewska M, Kraszpulski M, Konat GW: Kinetics of inflammatory response of astrocytes induced by TLR 3 and TLR4 ligation. J Neurosci Res 2007, 85:205-212.

10. Konat GW, Krasowska-Zoladek A, Kraszpulski M: Statins enhance toll-like receptor 4-mediated cytokine gene expression in astrocytes: implication of Rho proteins in negative feedback regulation. J Neurosci Res 2008, 86:603-609.

11. Liao CK, Wang SM, Chen YL, Wang HS, Wu JC: Lipopolysaccharide-induced inhibition of connexin43 gap junction communication in astrocytes is mediated by downregulation of caveolin-3. Int J Biochem Cell Biol 2010, 42:762-770

12. Gorina R, Font-Nieves M, Márquez-Kisinousky L, Santalucia T, Planas AM: Astrocyte TLR4 activation induces a proinflammatory environment through the interplay between MyD88-dependent NFkB signaling, MAPK, and Jak1/Stat1 pathways. Glia 2011, 59:242-255.

13. Amateau SK, McCarthy MM: Sexual differentiation of astrocyte morphology in the developing rat preoptic area. J Neuroendocrinol 2002. 14:904-910.

14. Suárez I, Bodega G, Rubio M, Fernandez B: Sexual dimorphism in the distribution of glial fibrillary acidic protein in the supraoptic nucleus of the hamster. J Anat 1991, 178:79-82.

15. Garcia-Segura LM, Dueñas M, Busiguina S, Naftolin F, Chowen JA: Gonadal hormone regulation of neuronal-glial interactions in the developing neuroendocrine hypothalamus. J Steroid Biochem Mol Biol 1995, 53:293-298.

16. Collado P, Beyer C, Hutchison JB, Holman SD: Hypothalamic distribution of astrocytes is gender-related in Mongolian gerbils. Neurosci Lett 1995, 184:86-89.

17. Mong JA, McCarthy MM: Steroid-induced developmental plasticity in hypothalamic astrocytes: Implications for synaptic patterning. I Neurobiol 1999, 40:602-619.

18. Kuo J, Hamid N, Bondar G, Dewing P. Clarkson J, Micevych P: Sex differences in hypothalamic astrocyte response to estradiol stimulation. Biol Sex Differ 2010, 1:7.

19. Suárez I, Bodega G, Rubio M, Fernández B: Sexual dimorphism in the hamster cerebellum demonstrated by glial fibrillary acidic protein (GFAP) and vimentin immunoreactivity. Glia 1992, 5:10-16.

20. Garcia-Segura LM, Suarez I, Segovia S, Tranque PA, Calés JM, Aquilera P, Olmos G, Guillamón A: The distribution of glial fibrillary acidic protein in the adult rat brain is influenced by the neonatal levels of sex steroids. Brain Res 1988, 456:357-363.

21. Rasia-Filho AA, Xavier LL, dos Santos P, Gehlen G, Achaval M: Glial fibrillary acidic protein immunodetection and immunoreactivity in the anterior and posterior medial amygdala of male and female rats. Brain Res Bull 2002, 58:67-75.

22. Johnson RT, Breedlove SM, Jordan CL: Sex differences and laterality in astrocyte number and complexity in the adult rat medial amygdala. $J$ Comp Neurol 2008, 511:599-609. 
23. Conejo NM, González-Pardo H, Cimadevilla JM, Argüelles JA, Díaz F, VallejoSeco G, Arias JL: Influence of gonadal steroids on the glial fibrillary acidic protein-immunoreactive astrocyte population in young rat hippocampus. J Neurosci Res 2005, 79:488-494

24. Arias C, Zepeda A, Hernández-Ortega K, Leal-Galicia P, Lojero C, CamachoArroyo I: Sex and estrous cycle-dependent differences in glial fibrillary acidic protein immunoreactivity in the adult rat hippocampus. Horm Behav 2009, 55:257-263.

25. Garcia-Segura LM, Chowen JA, Párducz A, Naftolin F: Gonadal hormones as promoters of structural synaptic plasticity: cellular mechanisms. Prog Neurobiol 1994, 44:279307.

26. Garcia-Segura LM: Hormones and Brain Plasticity New York: Oxford University Press; 2009.

27. Azad NA, Al Bugami M, Loy-English I: Gender differences in dementia risk factors. Gend Med 2007, 4:120-129.

28. Figueira ML, Ouakinin S: Gender-related endocrinological dysfunction and mental disorders. Curr Opin Psychiatry 2010, 23:369-372.

29. Jobin C, Larochelle C, Parpal H, Coyle PK, Duquette P: Gender issues in multiple sclerosis: an update. Womens Health (Lond Engl) 2010, 6:797-820

30. Melcangi RC, Garcia-Segura LM: Sex-specific therapeutic strategies based on neuroactive steroids: in search for innovative tools for neuroprotection. Horm Behav 2010, 57:2-11.

31. Voskuhl R: Sex differences in autoimmune diseases. Biol Sex Differ 2011, $2: 1$.

32. Liu M, Hurn PD, Roselli CE, Alkayed NJ: Role of P450 aromatase in sexspecific astrocytic cell death. J Cereb Blood Flow Metab 2007, 27:135-141.

33. Garcia-Segura LM, Veiga S, Sierra A, Melcangi RC, Azcoitia I: Aromatase: a neuroprotective enzyme. Prog Neurobiol 2003, 71:31-41.

34. Saldanha CJ, Duncan KA, Walters BJ: Neuroprotective actions of brain aromatase. Front Neuroendocrinol 2009, 30:106-118.

35. Garcia-Segura LM, Melcangi RC: Steroids and glial cell function. Glia 2006, 54:485-498.

36. Sinchak K, Mills RH, Tao L, LaPolt P, Lu JK, Micevych P: Estrogen induces de novo progesterone synthesis in astrocytes. Dev Neurosci 2003, 25:343-348.

37. Veiga S, Garcia-Segura LM, Azcoitia I: Neuroprotection by the steroids pregnenolone and dehydroepiandrosterone is mediated by the enzyme aromatase. J Neurobiol 2003, 56:398-406.

38. Ciriza I, Azcoitia I, Garcia-Segura LM: Reduced progesterone metabolites protect rat hippocampal neurones from kainic acid excitotoxicity in vivo. J Neuroendocrinol 2004, 16:58-63.

39. De Nicola AF, Labombarda F, Deniselle MC, Gonzalez SL, Garay L, Meyer M, Gargiulo G, Guennoun R, Schumacher M: Progesterone neuroprotection in traumatic CNS injury and motoneuron degeneration. Front Neuroendocrinol 2009, 30:173-187

40. Stein DG, Wright DW: Progesterone in the clinical treatment of acute traumatic brain injury. Expert Opin Investig Drugs 2010, 19:847-857.

41. Moralí G, Montes P, Hernández-Morales L, Monfil T, Espinosa-García C, Cervantes M: Neuroprotective effects of progesterone and allopregnanolone on long-term cognitive outcome after global cerebral ischemia. Restor Neurol Neurosci 2011, 29:1-15.

42. Dang J, Mitkari B, Kipp M, Beyer C: Gonadal steroids prevent cell damage and stimulate behavioral recovery after transient middle cerebral artery occlusion in male and female rats. Brain Behav Immun 2011, 25:715-726.

43. Itzhak Y, Roig-Cantisano A, Norenberg MD: Ontogeny of peripheral-type benzodiazepine receptors in cultured astrocytes and brain from rat. Brain Res Dev Brain Res 1995, 84:62-66.

44. Sierra A: Neurosteroids: the StAR protein in the brain. J Neuroendocrinol 2004, 16:787-793.

45. Lavaque E, Sierra A, Azcoitia I, Garcia-Segura LM: Steroidogenic acute regulatory protein in the brain. Neuroscience 2006, 138:741-747.

46. Papadopoulos V, Baraldi M, Guilarte TR, Knudsen TB, Lacapère JJ, Lindemann P, Norenberg MD, Nutt D, Weizman A, Zhang MR, Gavish M: Translocator protein (18 kDa): new nomenclature for the peripheral-type benzodiazepine receptor based on its structure and molecular function. Trends Pharmacol Sci 2006, 27:402-409.

47. Arnold AP, Gorski RA: Gonadal steroid induction of structural sex differences in the central nervous system. Annu Rev Neurosci 1984, 7:413-442.

48. Pistritto G, Franzese O, Pozzoli G, Mancuso C, Tringali G, Preziosi P, Navarra P: Bacterial lipopolysaccharide increases prostaglandin production by rat astrocytes via inducible cyclo-oxygenase: Evidence for the involvement of nuclear factor KB. Biochem Biophys Res Commun 1999, 263:570-574

49. Caruso D, D'Intino G, Giatti S, Maschi O, Pesaresi M, Calabrese D, GarciaSegura LM, Calza L, Melcangi RC: Sex-dimorphic changes in neuroactive steroid levels after chronic experimental autoimmune encephalomyelitis. J Neurochem 2010, 114:921-932.

50. Pesaresi M, Maschi O, Giatti S, Garcia-Segura LM, Caruso D, Melcangi RC: Sex differences in neuroactive steroid levels in the nervous system of diabetic and non-diabetic rats. Horm Behav 2010, 57:46-55.

51. Rone MB, Fan J, Papadopoulos V: Cholesterol transport in steroid biosynthesis: role of protein-protein interactions and implications in disease states. Biochim Biophys Acta 2009, 1791:646-658.

52. Garcia-Estrada J, Del Rio JA, Luquin S, Soriano E, Garcia-Segura LM: Gonadal hormones down-regulate reactive gliosis and astrocyte proliferation after a penetrating brain injury. Brain Res 1993, 628:271-278.

53. García-Estrada J, Luquín S, Fernández AM, Garcia-Segura LM: Dehydroepiandrosterone, pregnenolone and sex steroids down-regulate reactive astroglia in the male rat brain after a penetrating brain injury. Int J Dev Neurosci 1999, 17:145-151.

54. Grossman KJ, Goss CW, Stein DG: Effects of progesterone on the inflammatory response to brain injury in the rat. Brain Res 2004, 1008:29-39.

55. Barreto G, Veiga S, Azcoitia I, Garcia-Segura LM, Garcia-Ovejero D: Testosterone decreases reactive astroglia and reactive microglia after brain injury in male rats: role of its metabolites, oestradiol and dihydrotestosterone. Eur J Neurosci 2007, 25:3039-3046.

56. Gehlert DR, Stephenson DT, Schober DA, Rash K, Clemens JA: Increased expression of peripheral benzodiazepine receptors in the facial nucleus following motor neuron axotomy. Neurochem Int 1997, 31:705-713.

57. Rojas S, Martín A, Arranz MJ, Pareto D, Purroy J, Verdaguer E, Llop J, Gómez V, Gispert JD, Millán O, Chamorro A, Planas AM: Imaging brain inflammation with $\left[{ }^{11} \mathrm{C}\right] \mathrm{PK} 11195$ by PET and induction of the peripheraltype benzodiazepine receptor after transient focal ischemia in rats. $J$ Cereb Blood Flow Metab 2007, 27:1975-1986.

58. Chen MK, Guilarte TR: Translocator protein $18 \mathrm{kDa}$ (TSPO): molecular sensor of brain injury and repair. Pharmacol Ther 2008, 118:1-17.

59. Veiga S, Azcoitia I, Garcia-Segura LM: Ro5-4864, a peripheral benzodiazepine receptor ligand, reduces reactive gliosis and protects hippocampal hilar neurons from kainic acid excitotoxicity. J Neurosci Res 2005, 80:129-137.

60. Veiga S, Carrero P, Pernia O, Azcoitia I, Garcia-Segura LM: Translocator protein $18 \mathrm{kDa}$ is involved in the regulation of reactive gliosis. Glia 2007, 55:1426-1436.

61. Veenman L, Papadopoulos V, Gavish M: Channel-like functions of the 18$\mathrm{kDa}$ translocator protein (TSPO): regulation of apoptosis and steroidogenesis as part of the host-defense response. Curr Pharm Des 2007, 13:2385-2405.

62. Veenman L, Shandalov Y, Gavish M: VDAC activation by the $18 \mathrm{kDa}$ translocator protein (TSPO), implications for apoptosis. J Bioenerg Biomembr 2008, 40:199-205.

63. Sierra A, Lavaque E, Perez-Martin M, Azcoitia I, Hales DB, Garcia-Segura LM: Steroidogenic acute regulatory protein in the rat brain: cellular distribution, developmental regulation and overexpression after injury. Eur J Neurosci 2003, 18:1458-1467.

64. Lavaque E, Mayen A, Azcoitia I, Tena-Sempere M, Garcia-Segura LM: Sex differences, developmental changes, response to injury and CAMP regulation of the mRNA levels of steroidogenic acute regulatory protein, cytochrome p450scc, and aromatase in the olivocerebellar system. J Neurobiol 2006, 66:308-318.

65. Arnold AP: The organizational-activational hypothesis as the foundation for a unified theory of sexual differentiation of all mammalian tissues. Horm Behav 2009, 55:570-578.

66. Mong JA, Glaser E, McCarthy MM: Gonadal steroids promote glial differentiation and alter neuronal morphology in the developing hypothalamus in a regionally specific manner. J Neurosci 1999, 19:1464-1472.

67. Liu M, Oyarzabal EA, Yang R, Murphy SJ, Hurn PD: A novel method for assessing sex-specific and genotype-specific response to injury in astrocyte culture. J Neurosci Methods 2008, 171:214-217.

68. Farber JM: Mig and IP-10: CXC chemokines that target lymphocytes. J Leukoc Biol 1997, 61:246-257. 
69. Dufour JH, Dziejman M, Liu MT, Leung JH, Lane TE, Luster AD: IFN- $\gamma$ inducible protein 10 (IP-10; CXCL10)-deficient mice reveal a role for IP10 in effector T cell generation and trafficking. J Immunol 2002, 168:3195-3204.

70. Rothwell N: Interleukin-1 and neuronal injury: mechanisms, modification, and therapeutic potential. Brain Behav Immun 2003, 17:152-157.

71. Mason JL, Suzuki K, Chaplin DD, Matsushima GK: Interleukin-1 $\beta$ promotes repair of the CNS. J Neurosci 2001, 21:7046-7052.

72. Campbell IL, Abraham CR, Masliah E, Kemper P, Inglis JD, Oldstone MBA Mucke L: Neurologic disease in transgenic mice by cerebral overexpression of interleukin 6. Proc Natl Acad Sci USA 1993, 90:10061-10065.

73. Swartz KR, Liu F, Sewell D, Schochet T, Campbell I, Sandor M, Fabry Z: Interleukin-6 promotes post-traumatic healing in the central nervous system. Brain Res 2001, 896:86-95.

74. Penkowa M, Giralt M, Lago N, Camats J, Carrasco J, Hernandez J, Molinero A, Campbell IL, Hidalgo J: Astrocyte-targeted expression of IL-6 protects the CNS against a focal brain injury. Exp Neurol 2003, 181:130-148.

75. Quintana A, Molinero A, Borup R, Nielsen FC, Campbell IL, Penkowa M, Hidalgo J: Effect of astrocyte-targeted production of IL-6 on traumatic brain injury and its impact on the cortical transcriptome. Dev Neurobiol 2008, 68:195-208.

76. Syed MM, Phulwani NK, Kielian T: Tumor necrosis factor-a (TNF-a) regulates Toll-like receptor 2 (TLR2) expression in microglia. J Neurochem 2007, 103:1461-1471.

77. Worrall NK, Chang K, LeJeune WS, Misko TP, Sullivan PM, Ferguson TB, Williamson JR: TNF-a causes reversible in vivo systemic vascular barrier dysfunction via NO-dependent and -independent mechanisms. Am J Physiol 1997, 273:H2565-H2574.

78. Kim S, Steelman AJ, Koito H, Li J: Astrocytes promote TNF-mediated toxicity to oligodendrocyte precursors. J Neurochem 2011, 116:53-66

79. Su Z, Yuan Y, Chen J, Zhu Y, Qiu Y, Zhu F, Huang A, He C: Reactive astrocytes inhibit the survival and differentiation of oligodendrocyte precursor cells by secreted TNF-a. J Neurotrauma 2011, 28:1089-1100.

doi:10.1186/2042-6410-2-7

Cite this article as: Santos-Galindo et al: Sex differences in the inflammatory response of primary astrocytes to lipopolysaccharide. Biology of Sex Differences 2011 2:7.

\section{Submit your next manuscript to BioMed Central and take full advantage of:}

- Convenient online submission

- Thorough peer review

- No space constraints or color figure charges

- Immediate publication on acceptance

- Inclusion in PubMed, CAS, Scopus and Google Scholar

- Research which is freely available for redistribution

Submit your manuscript at www.biomedcentral.com/submit
Biomed Central 